\title{
Climate Change: The Karst Record (KR8) conference
}

\author{
Kathleen R. Johnson ${ }^{1}$ and Jay Banner ${ }^{2}$
}

Austin, USA, 21-24 May 2017

In recent decades, speleothems have become increasingly used as paleoclimate archives due to their suitability for precise $\mathrm{U}$-series dating, their fast and continuous growth, their broad geographic distribution, and the fact that they contain multiple proxies which are sensitive to environmental change. The rapid development of speleothem science (Fig. 1) has led, in particular, to major advances in our understanding of past hydroclimate variability. For instance, speleothems have provided detailed records of monsoon variability in Asia and South America, and have improved characterization of global teleconnections in response to orbital- and millennial-scale climate change (e.g. Cheng et al. 2009; Cruz et al. 2005; Wang et al. 2001). However, speleothem geochemical and physical properties reflect a complex, integrated signal of processes in the atmosphere, soil, epikarst, and caves (Fairchild et al. 2006). Robust interpretation of speleothem data, therefore, requires monitoring studies in active cave systems, often in combination with theory and modeling of speleothem processes.

The latest in speleothem-based paleoclimate records, cave monitoring, proxydevelopment, and modeling studies were presented at the 8th International "Climate Change: The Karst Record (KR8)" conference, which took place at the Jackson School of Geosciences, University of Texas at Austin. The conference, which has been the premier gathering of speleothem scientists since the initial meeting (KR1) in Bergen, Norway, in 1996, brought together 115 scientists from 18 countries for three days of oral and poster presentations (abstracts available at http://sites.uci.edu/kr8conference/scientificsessions), workshops and field trips. PAGES funding provided travel support for eight early-career scientists, including three from developing countries. The conference was organized around six themes: (1) Cave monitoring and climate proxy development, (2) High-resolution speleothem records, (3) Speleothem records of orbital to millennial scale climate variability, (4) Nove techniques, proxies, and unconventional archives, (5) Modeling in speleothem science, and (6) Speleothem proxy records in an Earth system context. Meeting attendees could choose to attend mid-conference workshops on: (1) Connecting climate models and paleo records, (2) Speleothem petrography, (3) Forward modeling of speleothem isotopes, and (4) Speleothem age modeling. Participants could also select from a variety of field trips to several central Texas cave locations studied by researchers from UT Austin (Banner et al. 2007; Feng et al. 2014; Meyer et al. 2014).

A pre-conference workshop, led by Amy Frappier (Skidmore College), on "Best Practices in Speleothem Science" was attended by 30 scientists. Discussion topics included trends and maturation of

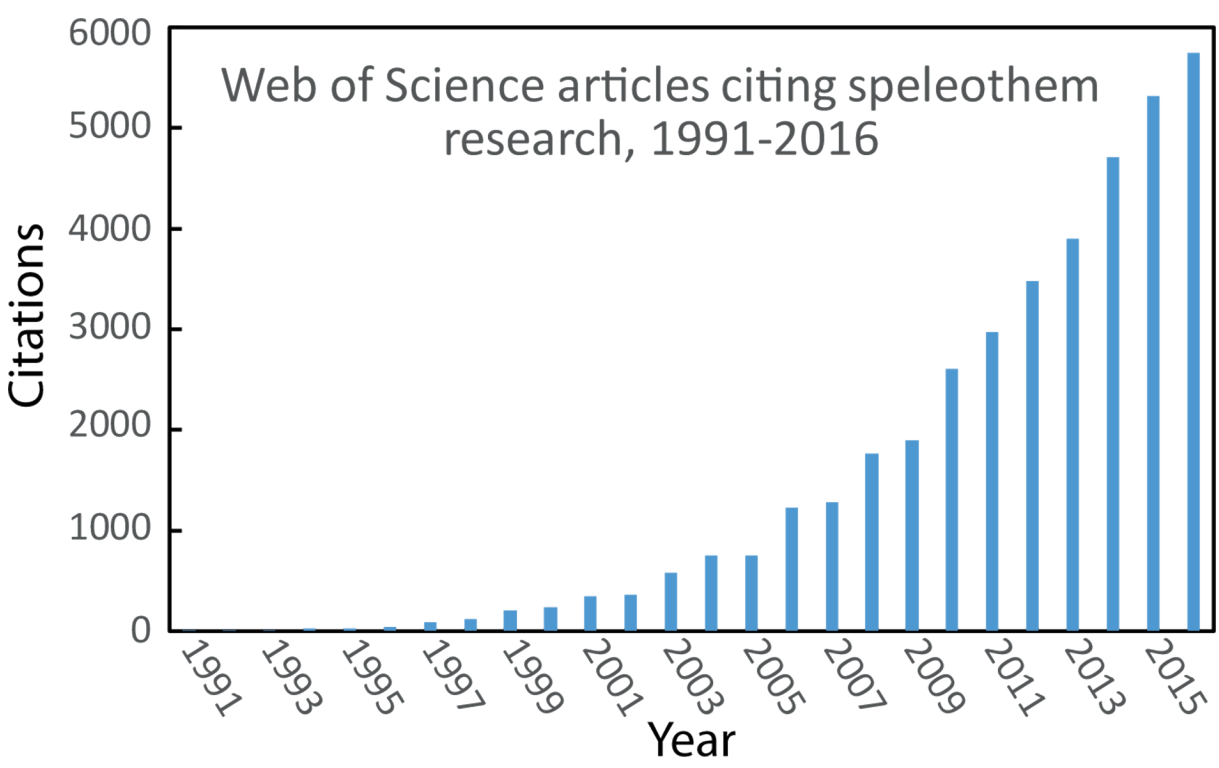

Figure 1: Web of Science search results showing the exponential increase in citations per year for articles that include the topics "speleothem" or "stalagmite" and "paleoclimate". This search returns a total of 1,483 articles that have been cited over 41,000 times. speleothem science, strategies for enhancing diversity within the field, and increasing public awareness of speleothem science. Significant discussion focused on strategies for minimizing impacts on cave environments and fostering strong and reciprocal relationships with cave managers and other stakeholders. One sentiment widely shared by attendees is the need for a coordinated effort to create a cave-sample database and archive. Obtaining funding and buy-in from the speleothem community will be necessary to achieve this goal. Finally, there was some discussion of data archiving and speleothem metadata, including participation in community initiatives such as SISAL (http://pastglobalchanges.org/ini/wg/sisal) and LinkedEarth (http://linked.earth). The key outcomes and recommendations stemming from this workshop will be the focus of a forthcoming white paper.

The KR8 conference continued the tradition of previous meetings in providing a forum for the presentation of cutting-edge speleothem-based paleoclimate research, including presentations of new records, detailed cave-monitoring studies, application of new methods and technologies to speleothem science, and strategies for improving interpretation of speleothem records through modeling studies. Furthermore, the meeting provided an excellent opportunity for networking and professional development of young researchers in the highly supportive and collaborative speleothem community. We look forward to the ninth "Climate Change: The Karst Record" meeting (KR9) which will be held at the University of Innsbruck, Austria, in 2020.

\section{AFFILIATIONS}

'Department of Earth System Science, University of California, Irvine, USA

2Jackson School of Geosciences, University of Texas at Austin, USA

\section{CONTACT}

Kathleen R. Johnson: kathleen.johnson@uci.edu

\section{REFERENCES}

Banner JL et al. (2007) J Sediment Res 77: 615-622

Cheng H et al. (2009) Science 326: 248-252

Cruz FW et al. (2005) Nature 434: 63-66

Fairchild IJ et al. (2006) Earth-Sci Rev 75: 105-153

Feng W et al. (2014) Geochim Cosmochim Acta 127: 233-250

Meyer KW et al. (2014) Geochim Cosmochim Acta 142: 281-298

Wang YJ et al. (2001) Science 294: 2345-2348 